\section{The diagnosis and management of}

\section{acute myeloid leukaemia}

\section{Donald W Milligan MD FRCP FRCPath, Consultant Haematologist and Honorary Senior Lecturer, Birmingham Heartlands Hospital}

\section{Clin Med JRCPL 2001;1:358-61}

Acute myeloid leukaemia (AML) is the commonest type of acute leukaemia in adults. About 1,800 cases occur annually in the UK, with an incidence of about three per 100,000. In the last 20 years there has been a steady improvement in the treatment of patients below the age of 60 (Fig 1), but over half the patients are over 60 (Fig 2) and their outlook remains poor. The aetiology is unknown in most cases, but AML is associated with pre-existing myelodysplasia (MDS), previous cytotoxic chemotherapy (particularly alkylating agents and epipodophyllotoxins), radiation, benzene exposure, constitutional chromosomal abnormalities and smoking.

\section{Clinical presentation and diagnosis}

Patients usually present with symptoms of bone marrow failure. In the absence of haemorrhage these symptoms can be quite non-specific and may only be of tiredness and malaise (Table 1). It is not unusual for patients to visit their general practitioner several times before the diagnosis is suspected.

The diagnosis is usually made on the discovery of leukaemic blast cells on a peripheral blood film and is confirmed by bone marrow examination. The leukocyte count is variable, in most patients ranging from $2-10 \times 10^{9} / 1$, although rarely it can exceed $300 \times 10^{9} / 1$. Bone marrow appearances may be characteristic, but the cell lineage is usually identified by cytochemistry and immunofluorescence using a panel of antibodies to specific myeloid and lymphoid antigens. The advent of immunodiagnosis has permitted clearer and less subjective identification of leukaemic subtypes. AML is usually classified by the French-AmericanBritish (FAB) classification (Table 2). Karyotyping of the cells is important since chromosomal abnormalities are increasingly used to predict outlook and direct therapy. Conventional metaphase analysis may miss some cryptic abnormalities, and fluorescence in situ
Fig 1. Medical Research Council trials for acute myeloid leukaemia: improvement in survival with time for patients aged 15-59 years (1970-1999).

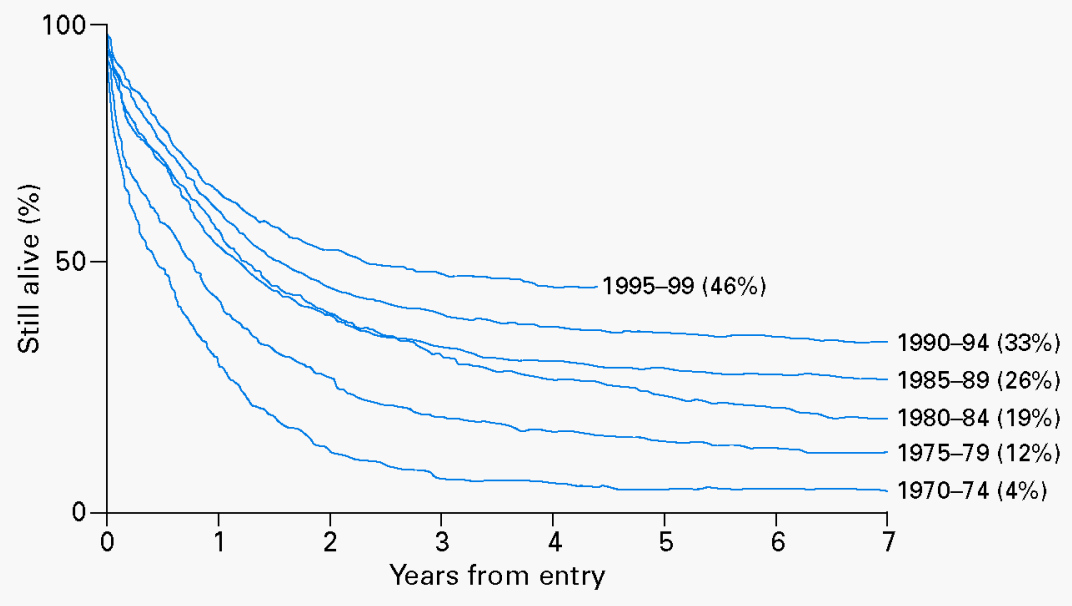

hybridisation or polymerase chain reaction (PCR) for $t(8 ; 21)$, inv $(16)$ and $t(15 ; 17)$ are frequently employed.

\section{Prognostic factors}

The key prognostic factors for survival are age and karyotype. Patients under 55 have an approximately $40 \%$ chance of cure, whereas it is $10 \%$ or less in those over 70, whose median survival is about eight months. The UK Medical Research Council (MRC) Leukaemia Trials Group $^{1}$ has defined high-, intermediateand low-risk groups depending on the karyotype (Table 3 ). These clearly segregate patients into different risk categories (Fig 3) and are now being used to define treatment strategies.

\section{Treatment of acute myeloid leukaemia}

The anthracycline daunorubicin combined with cytosine arabinoside has been the mainstay of AML therapy for 25 years. Other anthracyclines, for example idarubicin or mitoxantrone, may have some additional benefit. Classically, intravenous daunorubicin and cytosine are combined in a seven or ten day DA ' $3+7$ ' or ' $3+10$ ' regimen. Thioguanine or etoposide are added in the regimens DAT or ADE. Recently, cytosine has been combined with the purine analogue fludarabine with growth factor support (FLAG), particularly in salvage settings.

Antileukaemic chemotherapy is now given at near maximal tolerance, and patients require specialist nursing with single room isolation and intensive transfusion, microbiology and dietetic support. The British Committee for Standardisation in Haematology has recommended minimum standards of care for the treatment of acute leukaemia. There is, however, no evidence that the outcome (as measured by survival) is better for patients treated in larger units ${ }^{2}$. Patients require 3-5 cycles of chemotherapy, and may spend the best part of six months in hospital.

The aim of initial treatment is to achieve a remission, defined as normalisation of the peripheral blood count with fewer than $5 \%$ blast cells in the bone 
marrow. A remission will be achieved by $60-85 \%$ of patients with one to two cycles of treatment. Remission rates are better in younger patients than in the elderly. Post-remission treatment is aimed at eradicating disease undetectable by standard techniques in the hope of reducing the risk of relapse. Haematopoietic growth factors can be used both to 'prime' leukaemic cells to chemotherapy and as supportive care. Although their use may reduce the duration of neutropenia and fever, several large studies have failed to demonstrate improved remission rate or survival.

The available cytotoxic agents have changed little in recent years, but the doses used have considerably increased. There is now good evidence that increasing the cytosine dosage to 2-3 $\mathrm{g} / \mathrm{m}^{2} /$ day is associated with a reduced risk of relapse at least in younger patients ${ }^{3}$. An Intergroup trial in the $\mathrm{USA}^{4}$ showed that chemotherapy could produce results equivalent to autologous or allogeneic transplantation.

\section{Acute promyelocytic leukaemia}

Acute promyelocytic leukaemia (APML) is characterised by hypergranular promyelocytes and blasts. The leukaemic enzymes trigger intravascular coagulation with disseminated intravascular

Table 1. Presenting features of acute myeloid leukaemia.

Pathology Symptoms

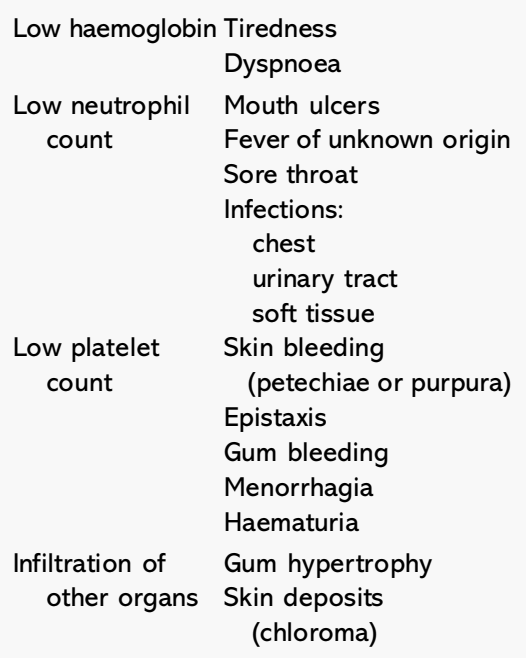

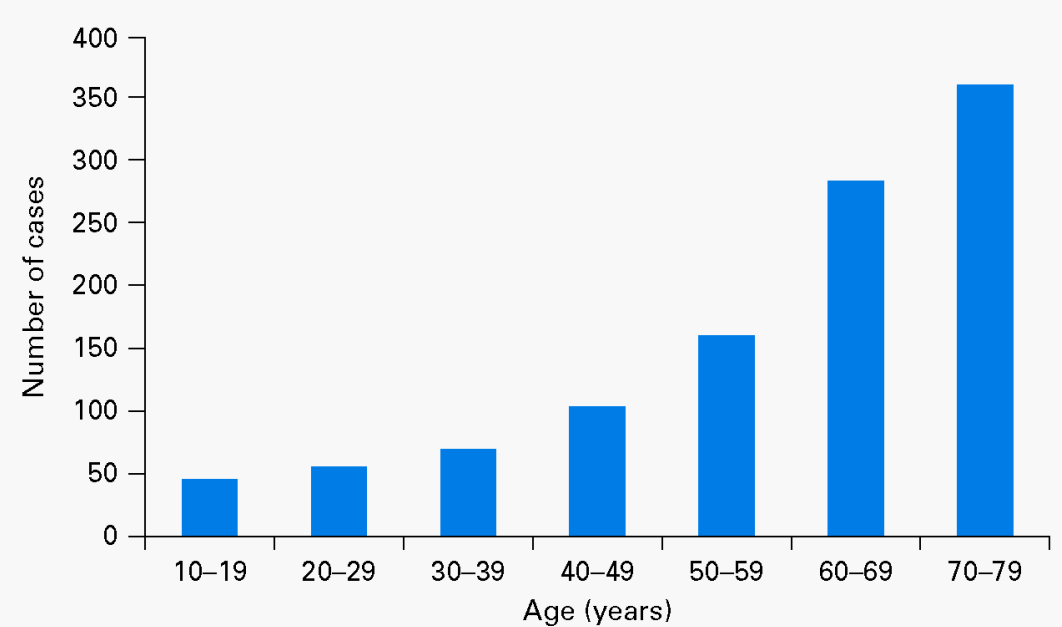

Fig 2. Annual incidence of acute myeloid leukaemia in England and Wales according to age. coagulation, and these patients can present as a haemorrhagic emergency. The karyotypic abnormality is well defined as a reciprocal translocation, $\mathrm{t}(15 ; 17)$ (q22; $\mathrm{q} 21)$, leading to the formation of $P M L-R A R \alpha$ and $R A R \alpha-P M L$ fusion genes. APML is highly sensitive to the oral differentiating agent all-trans retinoic acid (ATRA). Studies combining ATRA with chemotherapy show fewer early haemorrhagic deaths and fewer relapses, and approximately $70 \%$ of patients with APML can now be cured. There is also evidence that APML may not require the addition of cytosine, and that treatment with ATRA and anthracyclines alone produces good results with low morbidity ${ }^{5}$. PCR techniques for monitoring the fusion products of $t(15 ; 17)$ are useful both in detecting 'minimal residual disease' in patients in morphological remission and in pre-
Table 2. French-American-British (FAB) classification of acute myeloid leukaemia (AML) with genotype and clinical features.

\begin{tabular}{|c|c|c|c|c|}
\hline Leukaemia & FAB & $\%$ & Genotype & Clinical features \\
\hline $\begin{array}{l}\text { Acute myeloblastic } \\
\text { undifferentiated }\end{array}$ & MO & 7 & & Poorer outlook \\
\hline Acute myeloblastic & $\begin{array}{l}\text { M1 } \\
\text { M2 }\end{array}$ & $\begin{array}{l}13.5 \\
22.3\end{array}$ & $\begin{array}{l}\operatorname{inv}(3) \\
t(8 ; 21)\end{array}$ & Favourable prognosis \\
\hline Acute promyelocytic & M3 & 8.5 & $t(15 ; 17)$ & $\begin{array}{l}\text { Associated with disseminated } \\
\text { intravascular coagulation } \\
\text { Good prognosis further improved } \\
\text { with ATRA }\end{array}$ \\
\hline $\begin{array}{l}\text { Acute myelomonocytic } \\
\text { with eosinophils }\end{array}$ & $\begin{array}{l}\text { M4 } \\
\text { M4eo }\end{array}$ & 27.8 & $\operatorname{inv}(16)$ & $\begin{array}{l}\text { Extramedullary disease } \\
\text { As M4, good prognosis }\end{array}$ \\
\hline $\begin{array}{l}\text { Acute monocytic } \\
\text { undifferentiated }\end{array}$ & $\begin{array}{l}\text { M5 } \\
\text { M5a }\end{array}$ & 13 & $11 q 23$ & $\begin{array}{l}\text { Poorer prognosis } \\
\text { Extramedullary disease common }\end{array}$ \\
\hline differentiated & M5b & & & \\
\hline Erythroleukaemia & M6 & 5.3 & $\begin{array}{l}\operatorname{del}(5) \\
\operatorname{del}(7)\end{array}$ & $\begin{array}{l}\text { Poor prognosis } \\
\text { Older patients }\end{array}$ \\
\hline Acute megakaryoblastic & M7 & 2.7 & $\begin{array}{l}\operatorname{inv}(3), t(3 ; 3) \\
\text { trisomy } 21 \\
t(9 ; 22)\end{array}$ & $\begin{array}{l}\text { Difficult bone marrow aspirate } \\
\text { because of myelofibrosis } \\
\text { Poor prognosis } \\
\text { More common in AML in Down's } \\
\text { syndrome }\end{array}$ \\
\hline
\end{tabular}

ATRA $=$ all-trans retinoic acid 
Table 3. Cytogenetic risk groups for acute myeloid leukaemia.

Risk group Karyotype

$\begin{array}{ll}\text { Good } & \mathrm{t}(15 ; 17) \\ & \text { inv }(16) \\ & \mathrm{t}(8 ; 21) \\ \text { Standard } & \text { No abnormality } \\ & 11 q 23,+8,+21,+22 \\ & \text { del }(9 q), \text { del }(7 q) \\ & \text { Other structural or numerical } \\ & \text { defects not included in the } \\ & \text { good or poor risk groups } \\ \text { Poor } & \text { Complex karyotype } \\ & -5, \text { del }(5 q),-7\end{array}$

dicting relapse ${ }^{6}$. These methods may help to define the duration and type of post-remission treatment needed in some patients.

\section{Bone marrow transplantation}

\section{Autologous}

The different types of transplant are shown in Table 4. Early encouraging results with autologous transplantation in the 1980s have not been confirmed by large randomised trials ${ }^{7,8}$. The MRC AML 10 study showed an improvement in disease-free survival ${ }^{9}$, but the design suffered because the autograft was given as additional treatment, and it is possible that the same degree of benefit might have accrued from a further cycle of conventional therapy. Autografting failed to demonstrate the anticipated benefit probably for two reasons:

- It is likely that at least some of the relapses after this procedure are caused by re-infused malignant cells.

- The procedure carries treatmentrelated mortality (7-13\%) which reduces any gains.

\section{Allogeneic}

Allografting involves the donation of bone marrow or peripheral blood stem cells from a donor, usually an HLA identical sibling. This has the advantage of providing a graft uncontaminated with leukaemic cells and also carries a potential graft versus leukaemia effect due to donor allo-immune cytotoxic $\mathrm{T}$

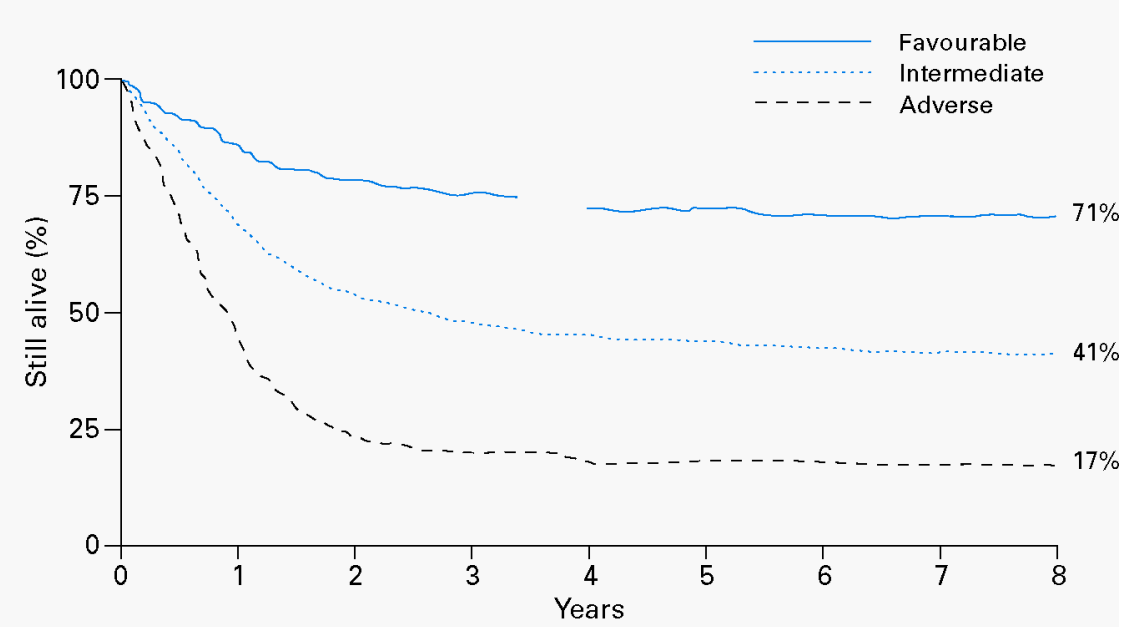

Fig 3. Survival in acute myeloid leukaemia according to cytogenetic risk group (from Ref 1 , with permission).

cells directed at the host leukaemia. There are several problems with allografting:

- Only about one-third of Western patients will have an HLA identical family donor (each sibling has a 1:4 chance of compatibility).

- The results are better for younger patients, usually under the age of 45 . Thus, allografting is not applicable to the vast majority of patients with AML.

- Transplant related mortality remains a problem, the main areas of concern being acute and chronic graft versus host disease and cytomegalovirus infection. The 100-day mortality for sibling allografts for AML in the International Bone Marrow Transplant Registry (IBMTR) database is about $14 \%$, with considerable variation between centres ${ }^{10}$. Newer techniques of low intensity or 'mini-allografting' are not yet explored in AML but may reduce the transplant related mortality and allow transplantation in older patients.

- Transplantation from unrelated donors is associated with greater risks, and is reserved for high-risk patients or patients in second remission.

As the results for chemotherapy have improved, the automatic assumption that younger patients with sibling donors should have a transplant has been challenged. The survival may be slightly better following transplantation, but this may be at the expense of a reduced quality of life $e^{11}$.

\section{Treatment of elderly patients}

The prognosis for older patients is poor due to a combination of comorbidities, frequent adverse karyotypes and preexisting MDS. Also, more patients express the multidrug resistance phenotype (MDR) which results in cytotoxic drug efflux from the leukaemic cell. It is possible that MDR expression may be overcome by the concurrent use of MDR inhibitors such as cyclosporin A or its

Table 4. Types of transplantation.

\begin{tabular}{ll}
$\begin{array}{c}\text { Transplantation } \\
\text { type }\end{array}$ & Donor \\
\hline $\begin{array}{l}\text { Autologous } \\
\text { Allogeneic }\end{array}$ & $\begin{array}{l}\text { Patient } \\
\text { Family: } \\
\text { HLA matched } \\
\text { (usually sibling) } \\
\text { HLA mismatched } \\
\text { Volunteer unrelated: } \\
\text { HLA matched } \\
\text { HLA mismatched } \\
\text { Syngeneic }\end{array}$ \\
\hline
\end{tabular}

In any transplant procedure the stem cell source can be from either bone marrow or circulating peripheral blood stem cells. 
analogue PSC 833, but there is no definitive clinical evidence for this.

Remission rates are lower in older patients, but the principal problem is disease relapse. It is by no means evident that all elderly patients with AML should receive chemotherapy, and the potential advantages and disadvantages need to be carefully discussed. Those likely to benefit are those with good performance status and intermediate or favourable risk chromosomes. The combination of calicheomicin with an anti-CD33 antibody (gemtuzomab-ozogamicin) may offer a less toxic approach, and trials both as a single agent and combined with chemotherapy are ongoing. Additional experimental treatments include topotecan, gemcitabine and liposomal daunorubicin.

\section{Summary}

Significant advances have been made in the management of AML in younger patients in the last 20 years, and it is easier to identify individual risk groups and stratify treatment accordingly. Results remain discouraging in the elderly, except for the minority with favourable risk factors, and new approaches are needed for most of these patients.

\section{References}

1 Wheatley K, Burnett AK, Goldstone AH, Gray RG, et al. A simple, robust, validated and highly predictive index for the determination of risk-directed therapy in acute myeloid leukaemia derived from the MRC AML 10 trial. United Kingdom Medical Research Council's Adult and Childhood Leukaemia Working Parties. Br J Haematol 1999;107:69-79.

2 Stiller CA, Benjamin S, Cartwright RA, Clough JV, et al. Patterns of care and survival for adolescents and young adults with acute leukaemia - a population-based study. Br J Cancer 1999;79:658-65.

3 Mayer RJ, Davis RB, Schiffer CA, Berg DT, et al. Intensive postremission chemotherapy in adults with acute myeloid leukemia. Cancer and Leukemia Group B. N Engl J Med 1994;331:896-903.

4 Cassileth PA, Harrington DP, Appelbaum FR, Lazarus HM, et al. Chemotherapy compared with autologous or allogeneic bone marrow transplantation in the management of acute myeloid leukemia in

Key Points

The outcome for acute myeloid leukaemia (AML) for younger patients has steadily improved and about $40 \%$ can now expect to be cured. The results for older patients remain poor

The most powerful prognostic factors for survival are age and chromosomal abnormalities

Management of AML requires intensive multidisciplinary team working, with skilled nursing, pharmacy, microbiology, blood banking, psychological and dietetic support

Autologous transplantation may improve disease-free survival, but does not improve overall survival

Allogeneic transplantation may improve outcome, but is applicable only to a small group of patients. Long-term survivors may have a reduced quality of life because of graft versus host disease, cataracts and infertility

The main problem remains drug resistance, and new strategies are needed to overcome this

Trials of an anti-CD33 antibody monoclonal antibody tagged to a cytotoxic anthracycline are underway

first remission. $N$ Engl J Med 1998;339: 1649-56.

5 Sanz MA, Lo Coco F, Martin G, Avvisati G, et al. Definition of relapse risk and role of nonanthracycline drugs for consolidation in patients with acute promyelocytic leukemia: a joint study of the PETHEMA and GIMEMA cooperative groups. Blood 2000;96:1247-53.

6 Burnett AK, Grimwade D, Solomon E, Wheatley K, Goldstone AH. Presenting white blood cell count and kinetics of molecular remission predict prognosis in acute promyelocytic leukemia treated with all-trans retinoic acid: result of the Randomized MRC Trial. Blood 1999;93: 4131-43.

7 Zittoun RA, Mandelli F, Willemze R, de Witte $\mathrm{T}$, et al. Autologous or allogeneic bone marrow transplantation compared with intensive chemotherapy in acute myelogenous leukemia. European Organization for Research and Treatment of Cancer (EORTC) and the Gruppo Italiano Malattie Ematologiche Maligne dell'Adulto (GIMEMA) Leukemia Cooperative Groups. N Engl J Med 1995; 332:217-23.

8 Harrousseau JL, Cahn J-Y, Pignon B, Witz F, et al. Comparison of autologous transplantation and intensive chemotherapy as postremission therapy in adult acute myeloid leukemia. Blood 1997;90:2978-86.
9 Burnett AK, Goldstone AH, Stevens RM, Hann IM, et al. Randomised comparison of addition of autologous bone-marrow transplantation to intensive chemotherapy for acute myeloid leukaemia in first remission: results of MRC AML 10 trial. UK Medical Research Council Adult and Children's Leukaemia Working Parties. Lancet 1998; 351:700-8.

10 Frassoni F, Labopin M, Powles R, Mary JY, et al. Effect of centre for outcome of bonemarrow transplantation for acute myeloid leukaemia. Acute Leukaemia Working Party of the European Group for Blood and Marrow Transplantation. Lancet 2000;355: 1393-8.

11 Watson M, Wheatley K, Harrison GA, Zittoun $\mathrm{R}$, et al. Severe adverse impact on sexual functioning and fertility of bone marrow transplantation, either allogeneic or autologous, compared with consolidation chemotherapy alone: analysis of the MRC AML 10 trial. Cancer 1999;86:1231-9.

Address for correspondence:

Dr Donald W Milligan, Consultant

Haematologist and Honorary Senior

Lecturer, Birmingham Heartlands

Hospital, Birmingham B9 5SS.

E-mail: d.w.milligan@bham.ac.uk 